\title{
A Game Mechanism of Individual Value Decision-Making Based on SVO Differences
}

\author{
Xu Shi, ${ }^{1}$ Lu-yun Qiu, ${ }^{2}$ Zhi-geng Fang $\mathbb{D}^{2},{ }^{2}$ Xia-qing Liu $\mathbb{D}^{2,3}$ and Yang-yang $\mathrm{Du}^{2}$ \\ ${ }^{1}$ Student Affairs Office, Nanjing University of Aeronautics and Astronautics, Nanjing 211100, China \\ ${ }^{2}$ College of Economics and Management, Nanjing University of Aeronautics and Astronautics, Nanjing 211100, China \\ ${ }^{3}$ Shandong Technology and Business University, Yantai 264005, China
}

Correspondence should be addressed to Zhi-geng Fang; zhigengfang@163.com

Received 4 June 2020; Accepted 25 July 2020; Published 25 August 2020

Academic Editor: Dimitri Volchenkov

Copyright $\odot 2020 \mathrm{Xu}$ Shi et al. This is an open access article distributed under the Creative Commons Attribution License, which permits unrestricted use, distribution, and reproduction in any medium, provided the original work is properly cited.

\begin{abstract}
As the externalized carrier of intrinsic value, value decision-making is an important factor affecting the social value system. As an old Chinese saying goes, "A friend in need is a friend indeed," crisis environment provides the background for the conflicts of multiple values, while individual social value orientation (SVO) determines the ranking of the value states. This paper defined the SVO types by means of Slider Measure method on the basis of environment description, constructed a decision-making game model in accordance with SVO differences, and finally analysed the mechanism of people's decision-making. Taking the epidemic situation as the background, this paper conducted an empirical analysis with the sample of college students. The results showed that the most SVO types of college students were prosocial orientation, followed by individualistic orientation, altruistic orientation, and competitive orientation. In the crisis environment, individual SVO type and decision-making constituted a mapping relationship. There was an equilibrium point in the decision of prosocial orientation, and the dominant decision of altruistic orientation or individualistic orientation is relatively stable.
\end{abstract}

\section{Introduction}

The nature of a human being is not the inherent abstraction of a single person. In fact, it is the sum of all social relations. [1] Values are unique to human beings and can be an important measure of people's moral concept and behaviour choice. There is no doubt that it will be affected by the social environment and the changes of the times. Nowadays, modernization, globalization, and marketization have led to value conflicts between tradition and modernity and foreign and native cultures, which in turn results in a variety of new challenges such as the diversification of value culture and standards [2]. In this case, individual values and value orientations, judgments, and decisions are full of uncertainty. The construction of the people's spiritual world and the establishment and maintenance of a good social order depend on the core values of community members [3]. A correct understanding of the impact factors, characteristics, and mechanisms of people's decision-making in social environment will help to analyse the complex and fluid social order and eliminate the risk factors restricting the development of the society.

In order to achieve the above goals, first of all, we should pay attention to the individual as the subject of behaviour, especially the difference of value orientation. The reason why individuals have value conflicts is that their consciousness contains two or multiple value forms (such as collective and individual and material and spirit) [4]. In the face of diversified value states, individuals must make order according to their value orientation or preference, which is directly related to the result of value selection [5]. People's social life is inseparable from decision-making. Faced with diversified value states, people will make a ranking according to their value orientation or preference, which is directly related to decision-making [5]. Therefore, as a relatively stable judgment of the event value, the study of value orientation is of great significance for understanding decision-making. At present, the research mainly focuses on the development and 
change of value orientation, regional comparison and other actual states [6-8], and the due state of "truth, goodness, and beauty" [9-11] and focuses on students and other young groups. As for the research on its causal state, there is a "rational man hypothesis" in traditional theory, which holds that individuals are driven by self-interest and pursue the maximization of self-interest. This classical theory has certain limitations, focusing excessively on individuals and ignoring social relations [12]. In view of this, some scholars proposed the theory of social value orientation (SVO), holding that social value orientation (SVO) is a relatively stable personality trait [13], which can describe the concept of individual differences of individuals' specific preference for the distribution of interests between themselves and others in the decision-making context $[14,15]$.

Secondly, attention should be paid to the decisionmaking environment, especially the crisis environment. As a kind of inner scale, individual value orientation has the implicit characteristics, which is difficult to be perceived or observed in daily life. The reason why literary novels are attractive is which writers tend to design plots with conflicts, place characters in crisis environment, magnify the contradictions, and show the complex humanity and core orientation. This is precisely because crisis environment can provide a background for the existence and conflict of multiple values $[16,17]$. Therefore, it is very necessary to set up crisis environment when exploring people's value decision.

Research on crisis environment mainly focuses on social dilemma [18] and moral dilemma [19, 20]. Theoretically, the structure of self-moral or nonself-moral dilemma [21] and high-low conflict moral dilemma [22] are divided. In practice, the "dilemma teaching method" is adopted for moral education [23-25], and the "Bohr model" [26] and the "Kidder model" [27] are proposed for ethical dilemma choice mode. The above research studies mainly focus on the framework structure of the crisis environment itself, which is relatively theoretical, or provide formulated decision-making methods for individuals in the crisis environment, with strong operability. However, they seldom combine the theoretical and operational aspects and have not provided mechanism and case analysis for how the crisis environment affects individual value decision-making.

Thirdly, the interaction between people of different SVO types and the crisis environment should be analysed. The crisis environment provides a background for the conflict of multiple values, and individual value orientation determines the weight order and strategic choice of decision factors, that is, there is some mapping relationship between the individual's behaviour choice and its value orientation.

Some scholars proposed that different individuals, faced with the same decision-making environment, would subjectively give weight to the profit and loss involving themselves and others based on their own value orientation and preference. Instead of the original matrix, the decisionmaking behaviour is based on the decision maker's subjective utility matrix [28-31]. Most of the existing studies focus on the qualitative description of the impact of the environment on individuals and their behaviours and the educational function of the environment $[32,33]$, and there are relatively few studies on the generation procedure and interaction mechanism of optimal decision-making in the crisis environment.

\section{Game Model Construction}

Generally speaking, in an environment that does not involve too many overlapping interests, the social value orientation of most people is introverted, with little difference in value judgment and decision-making and indistinguishable distinction. However, in the severe crisis environment, such as natural disaster and sudden danger, the individual's deep core value orientation can be revealed through the greatly different value decision and result.

Due to the differences in economic conditions, family environment, and growth experience, people have unique value pursuit, evaluation, ranking, selection, and realization methods. Social preference theory believes that SVO is jointly determined by self-interest, the benefits of others, and the equality of the benefits of both parties and then proposes the existence of "cooperation (to pursue the maximization of collective interests), equality (to pursue the minimization of the relative interests of both parties), altruism (to pursue the maximization of others), individuals (to pursue the maximization of absolute self-interests), competition (to pursue the maximization of relative self-interests), and attack (to pursue the minimization of interests of others) a total of 6 types of SVO $[34,35]$. The first three types are collectively known as prosocial orientation, and the second three types are collectively known as proself orientation [36, 37]. In crisis environment, individuals with different SVO types will transform the objective situation into subjective cognition according to their internal norms, form a series of value states, and make ranking and selection according to the principle of trust. A large number of studies have shown that, under the influence of SVO, individuals with prosocial orientation give priority to "trusting and cooperative" in their value decision-making [38-40].

Game theory, as a method to study the interaction between formulaic incentive structures, can bridge the decision makers and the social environments. The benefits including losses of individuals on different selection strategies under crisis environment are transformed into the subjective utility matrix of the game model, and quantitative analysis is carried out. By calculating the equilibrium point of the game, this paper analyses the mapping relationship between the decisions and people's SVO types in crisis environment and the game mechanism.

2.1. Environmental Description. Before making decisions, individuals first need to have a relatively clear understanding of the crisis environment they are in and comprehensively grasp the objective situation, which includes understanding the existence of multiple stakeholders in a particular environment, the space available for making value choices, the possibility of conflicts between different choices, and relevant influencing factors and their relationships. 
2.2. Determining the Types of SVO. At present, the research methods for evaluating individual SVO types mainly include Triple-Dominance Measure, the Loop Measure, and the SVO Slider Measure. As a newly developed test tool, the main advantages of the SVO Slider Measure [41] developed by Murphy et al. are the construction of six test items reflecting four common SVO types (altruistic, prosocial, individualistic, and competitive). This method can reduce the interference effect of rare types and improve the efficiency of main type distinguishing, and the measure can be scored in a straightforward manner to yield a single index of SVO, based on which a full ranking of preferences over motivations can be obtained.

The test assumes that there are only two roles, namely, the subject and the virtual other. The measure has six primary items with nine secondary or optional items. The subject is the distributor of a given benefit (e.g., 150 yuan), and the individual needs to judge the benefit of himself and others. If $X$ is selected, the benefit of others will be $150-X$. The decision maker would indicate his or her allocation choice by marking a line at the point that defines their most preferred joint distribution, as shown in Figure 1.

The primary item is the subject of the test, mainly derived from the circle with a centre of $(50,50)$ and a radius of 50, as shown in Figure 2. In the figure, the horizontal and vertical coordinates, respectively, represent the benefits of self and others. After the selection, a single index of a person's SVO can be calculated. The calculation formula is as follows:

$$
\mathrm{SVO}^{\circ}=\operatorname{acr} \tan \left(\frac{\bar{P}_{o}-50}{\bar{P}_{s}-50}\right),
$$

where $\bar{P}_{o}$ is the mean of one's own earnings and $\bar{P}_{s}$ is the mean of the earnings of others.

The result is a one-dimensional continuous variable. The larger the value is, the more the decision maker cares about others' benefits. The range is $-16.26^{\circ} \sim 61.39^{\circ}$.

According to the definition of the formula and the meaning of SVO angle, four angle intervals can be distinguished in correspondence with four idealized SVO types.

2.3. Constructing a Game Model. First, make assumptions about the game model. The basic components of game theory are

(i) Player, the decision maker who choose strategies to optimize their utility value

(ii) Strategy, the decision of the players

(iii) Information, the player's perception of game characteristics and the actions of another player

(iv) Payment function, the level of utility value that the players get from the game

(v) Results, the game analysis and information of interest to researchers

(vi) Equilibrium, the optimal strategy or action combination of the players in the game
Based on the above concept, the value decision-making game model based on SVO difference in crisis environment can be described as follows. In this game, the environment exists as a virtual player 1 with K-behavioural strategies, that is, the manifestation of different states of affairs; the individual participant with SVO type $\mathrm{N}$ exists as player 2, and four SVO types are obtained based on the Slider Measure; player 2 has $u$ strategies. It is assumed that both players 1 and 2 are rational and jointly pursue the maximization of their own interests. Moreover, due to the progress of information technology, individual participants have a higher and higher degree of information mastery over a specific environment, even reaching the definition requirements of complete information game. In addition, individual participants usually choose strategies only based on their own judgment before acting and do not rely on the information of other players' strategic behaviours. Therefore, the game model is a static game with complete information.

Then, the framework and mechanism of the game model are analysed. The profit and loss variables in the model are set as follows:

(i) Social value orientation type $/ \mathrm{Svo}_{N}$ : altruistic, prosocial, individualistic, and competitive orientation $(N=\mathrm{A}, \mathrm{B}, \mathrm{C}, \mathrm{D})$.

(ii) Environment type $/ E n_{K}$ : the environment exists as a virtual player 1 with $K$ strategies.

(iii) Strategies under SVO type $/ S t_{N u}$ : a person with SVO type $N$ exist as player 2 with $u$ strategies.

(iv) Payment function $/ K_{N u}$ : under the environment type $K$, the player 2 with the SVO type $N$ selects the strategy $u$. The function has three independent variables: $E n_{K}, S v_{N}$, and $S t_{N u}$, that is, these variables (environment type, SVO type, and strategy) have a corresponding relationship to the payment function, which is written as $K_{N u}=f_{K N u}$ $\left\{E n_{K}, S t_{N u} / \mathrm{Svo}_{N}\right\}$, where "St$t_{N u} / \mathrm{Svo}_{N}$ " means "strategy under a given SVO type."

(v) Game module/SVON: each SVO type corresponds to a payment matrix. Therefore, the number of game modules is the same as the SVO types.

According to above information, the game matrix can be constructed, as shown in Figure 3.

2.4. Equilibrium Analysis of Decision-Making. First, construct the subjective utility function. In order to look for equilibrium solutions and analyse key variables under different environments, SVO types, and strategies, the three impact factors $\left(E n_{K}, S v o_{N}\right.$, and $\left.S t_{n u}\right)$ are converted into the related expressions of $P_{K u}^{N}$ (Payments) and $G_{K u}^{N}$ (Gains) for a person of type SVON selecting strategy $u$ under environment $K$ :

$$
Y_{K u}^{N}=f\left(P_{K u}^{N}, G_{K u}^{N}\right)=a_{K u}^{N} \cdot G_{K u}^{N}-b_{K u}^{N} \cdot P_{K u}^{N},
$$

where $Y_{K u}^{N}$ is the subjective utility function value of people with SVO type $\mathrm{N}$ selecting strategy $u$ under environment $K$ and $P_{K u}^{N}$ is the total efforts or payments of the person, 


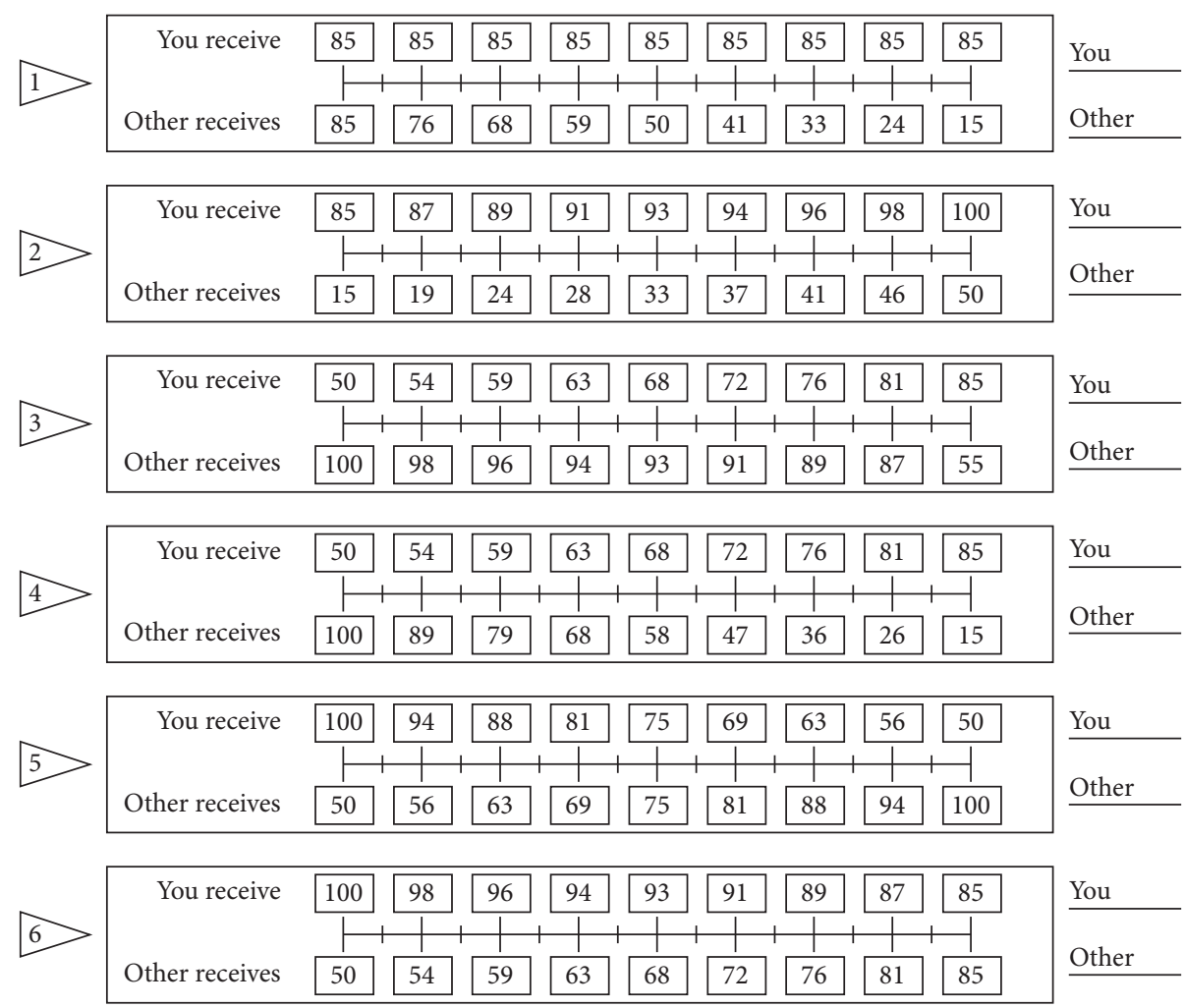

Figure 1: The six primary SVO Slider items (quoted from Murphy [41]).

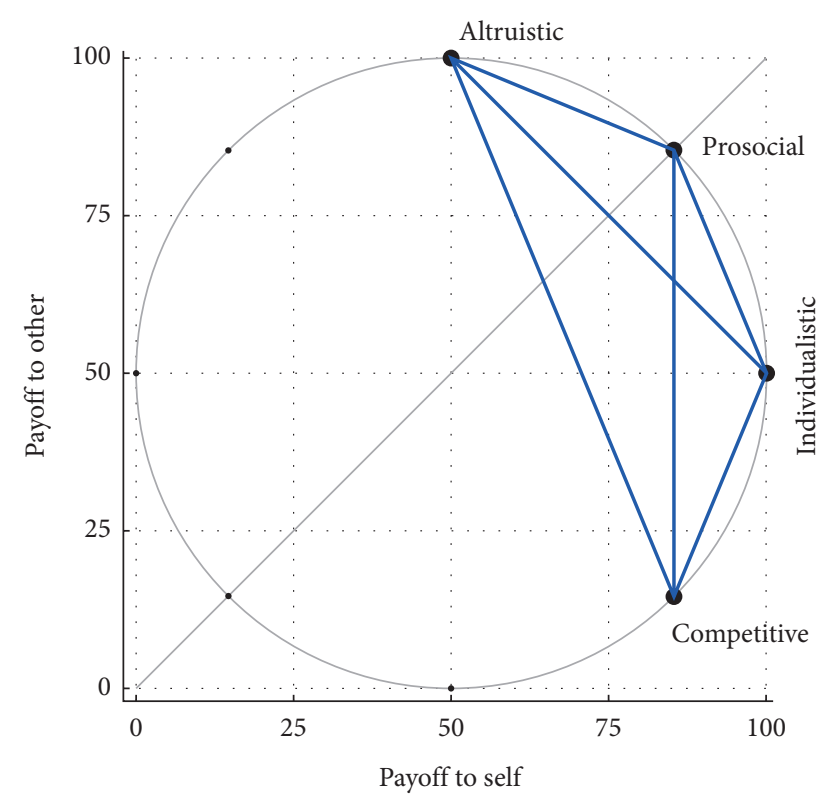

FIGURE 2: In the self/other allocation plane the six primary items are from the Slider Measure (picture quoted from Murphy [41]).

including the costs of time, economy, and risk. Correspondingly, $G_{K u}^{N}$ is his/her obtains or gains, including commendation, spiritual satisfaction, and social contribution. $a_{K u}^{N}$ is the coefficient of the gains in the utility function $\left(a_{K u}^{i}>0\right)$. Correspondingly, $b_{K u}^{N}$ is the coefficient of the payments in the function $\left(b_{K u}^{i}>0\right)$.
Then, carry on the equilibrium analysis. To simplify the solution process, let $K=2$ and $u=2$ which means there are 2 strategies in the research environment: strategy 1 (normal) and strategy 2 (crisis), and an individual has 2 strategies: strategy 1 (prosocial) and strategy 2 (proself). Suppose that the probability of individual participants adopting "strategy 1 " is $\alpha$ and that adopting "strategy 2 " is $1-\alpha$. The probability of adopting "environment strategy 1 " is $\beta$, and the probability of "environment strategy 1 " is $1-\beta$. The payment matrix is constructed, as shown in Figure 4.

According to equation (2) and Figure 4, the following formula can be obtained:

$$
\begin{aligned}
& Y_{11}^{N}=f\left(G_{11}^{N}, P_{11}^{N}\right)=a_{11}^{N} \cdot G_{11}^{N}-b_{11}^{N} \cdot P_{11}^{N}, \\
& Y_{12}^{N}=f\left(G_{12}^{N}, P_{12}^{N}\right)=a_{12}^{N} \cdot G_{12}^{N}-b_{12}^{N} \cdot P_{12}^{N}, \\
& Y_{21}^{N}=f\left(G_{21}^{N}, P_{21}^{N}\right)=a_{21}^{N} \cdot G_{21}^{N}-b_{21}^{N} \cdot P_{21}^{N}, \\
& Y_{22}^{N}=f\left(G_{22}^{N}, P_{22}^{N}\right)=a_{22}^{N} \cdot G_{22}^{N}-b_{22}^{N} \cdot P_{22}^{N} .
\end{aligned}
$$

Based on the game matrix and the principle of indifference on difference strategies, the equilibrium conditions are set up.

The total utility of a person of SVO-type NSVO.N adopting "strategy 1 " $/ E_{K 1}^{N}$ :

$$
\begin{aligned}
E_{K 1}^{N}= & \beta \cdot Y_{11}^{N}+(1-\beta) \cdot Y_{21}^{N} \\
= & \beta \cdot\left(a_{11}^{N} \cdot G_{11}^{N}-b_{11}^{N} \cdot P_{11}^{N}\right) \\
& +(1-\beta) \cdot\left(a_{21}^{N} \cdot G_{21}^{N}-b_{21}^{N} \cdot P_{21}^{N}\right) .
\end{aligned}
$$



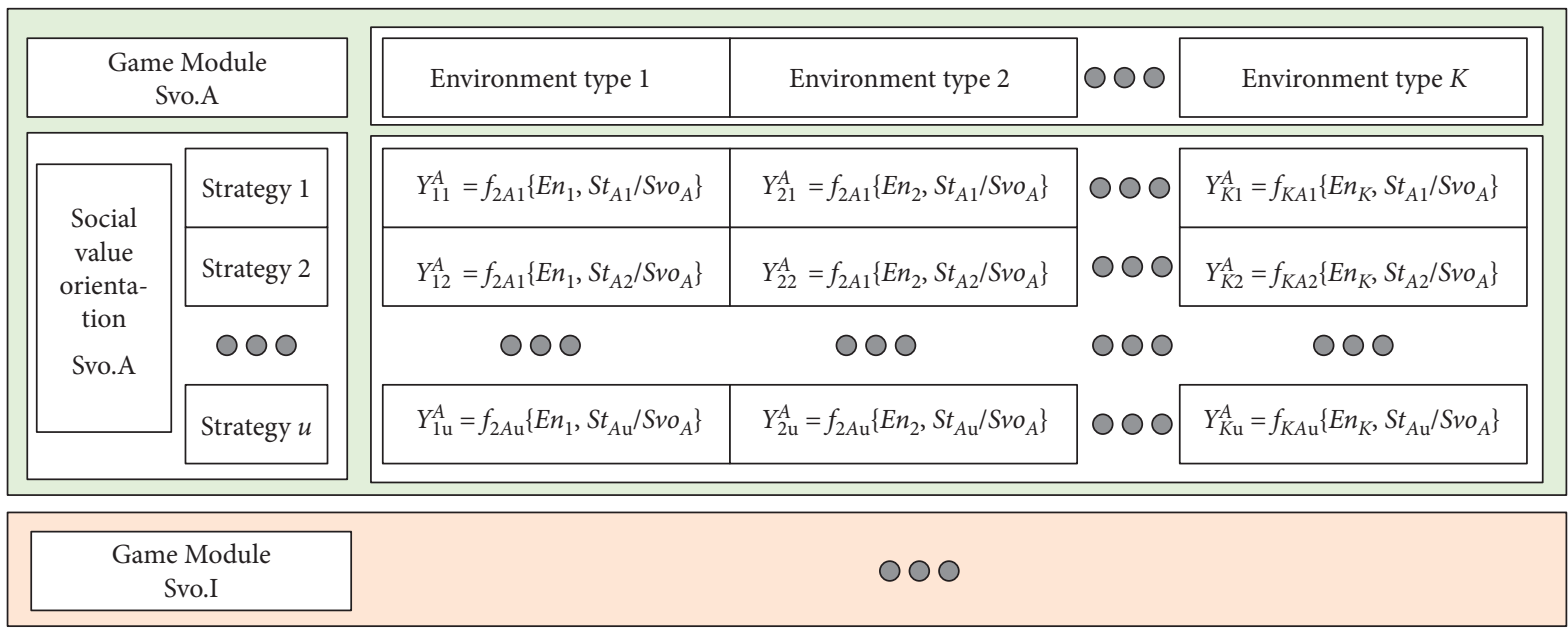

\begin{tabular}{|c|c|c|c|c|c|}
\hline \multicolumn{2}{|c|}{$\begin{array}{c}\text { Game Module } \\
\text { Svo.N }\end{array}$} & Environment type 1 & Environment type 2 & 000 & Environment type $\mathrm{K}$ \\
\hline \multirow{4}{*}{$\begin{array}{l}\text { Social } \\
\text { value } \\
\text { orienta- } \\
\text { tion } \\
\text { Svo.N }\end{array}$} & Strategy 1 & $Y_{11}^{N}=f_{2 N 1}\left\{E n_{1}, S t_{N 1} / S v o_{N}\right\}$ & $Y_{21}^{N}=f_{2 N 1}\left\{E n_{2}, S t_{N 1} / S v o_{N}\right\}$ & \multirow{2}{*}{$\begin{array}{l}000 \\
000\end{array}$} & $Y_{K 1}^{N}=f_{K N 1}\left\{E n_{K}, S t_{N 1} / S v o_{N}\right\}$ \\
\hline & Strategy 2 & $Y_{12}^{N}=f_{2 N 1}\left\{E n_{1}, S t_{N 2} / S v o_{N}\right\}$ & $Y_{22}^{N}=f_{2 N 1}\left\{E n_{2}, S t_{N 2} / S v o_{N}\right\}$ & & $Y_{K 2}^{N}=f_{K N 2}\left\{E n_{K}, S t_{N 2} / S v o_{N}\right\}$ \\
\hline & 000 & 000 & 000 & 000 & 000 \\
\hline & Strategy $u$ & $Y_{1 \mathrm{u}}^{N}=f_{2 N \mathrm{u}}\left\{E n_{1}, S t_{N \mathrm{u}} / S v o_{N}\right\}$ & $Y_{2 \mathrm{u}}^{N}=f_{2 N \mathrm{u}}\left\{E n_{2}, S t_{N \mathrm{u}} / S v o_{N}\right\}$ & 000 & $Y_{K \mathrm{u}}^{N}=f_{K N \mathrm{u}}\left\{E n_{K}, S t_{N \mathrm{u}} / S v o_{N}\right\}$ \\
\hline
\end{tabular}

FIGURE 3: The decision-making game matrix in crisis environment based on SVO differences.

\begin{tabular}{|c|c|c|}
\hline \multirow[b]{3}{*}{$\begin{array}{c}\text { Strategy 1: } \quad(\alpha) \\
\text { prosocial }\end{array}$} & \multicolumn{2}{|c|}{ Player 1(virtual): environment } \\
\hline & Strategy 1: normal $(\beta)$ & Strategy 2: crisis $(1-\beta)$ \\
\hline & $Y_{11}^{N}=f\left(G_{11}^{N}, P_{11}^{N}\right)$ & $Y_{21}^{N}=f\left(G_{21}^{N}, P_{21}^{N}\right)$ \\
\hline $\begin{array}{l}\text { Strategy 2: } \\
\text { proself } \\
(1-\alpha)\end{array}$ & $Y_{12}^{N}=f\left(G_{12}^{N}, P_{12}^{N}\right)$ & $Y_{22}^{N}=f\left(G_{22}^{N}, P_{22}^{N}\right)$ \\
\hline
\end{tabular}

FIGURE 4: Simplified game matrix.

The total utility of a person of SVO-type NSVO.N adopting “Strategy 2 ” $E_{K 2}^{N}$ :

$$
\begin{aligned}
E_{K 2}^{N}= & \beta \cdot Y_{12}^{N}+(1-\beta) \cdot Y_{22}^{N}=\beta \cdot\left(a_{12}^{N} \cdot G_{12}^{N}-b_{12}^{N} \cdot P_{12}^{N}\right) \\
& +(1-\beta) \cdot\left(a_{22}^{N} \cdot G_{22}^{N}-b_{22}^{N} \cdot P_{22}^{N}\right) .
\end{aligned}
$$

From $E_{K 1}^{N}=E_{K 2}^{N}$,

$$
\begin{aligned}
& \beta \cdot\left(a_{11}^{N} \cdot G_{11}^{N}-b_{11}^{N} \cdot P_{11}^{N}\right)+(1-\beta) \cdot\left(a_{21}^{N} \cdot G_{21}^{N}-b_{21}^{N} \cdot P_{21}^{N}\right) \\
& =\beta \cdot\left(a_{12}^{N} \cdot G_{12}^{N}-b_{12}^{N} \cdot P_{12}^{N}\right)+(1-\beta) \cdot\left(a_{22}^{N} \cdot G_{22}^{N}-b_{22}^{N} \cdot P_{22}^{N}\right) .
\end{aligned}
$$

The strategy of a person of SVO-type NSVO.N achieves equilibrium in the decision-making game model.

From the perspective of model solution, only by analysing the existence of the equilibrium solution and identifying the key variables that affect the behavioural probability of individual participants can the game mechanism behind value judgment and selection of individuals of different SVO types in crisis environment be grasped more accurately.

Proposition 1. If $Y_{22}^{N}>Y_{21}^{N}$ and $Y_{11}^{N}>Y_{12}^{N}$ or if $Y_{22}^{N}<Y_{21}^{N}$ and $Y_{11}^{N}<Y_{12}^{N}$, an equilibrium solution exists.

Proof. According to $E_{K 1}^{N}=E_{K 2}^{N}$, we can deduce $\beta / 1-$ $\beta=\left(Y_{22}^{N}-Y_{21}^{N}\right) / Y_{11}^{N}-Y_{12}^{N}$. As $\beta$ is the probability of "strategy 1 ," there is $0<\beta<1$. Only this equation satisfies the condition $\beta / 1-\beta=\left(Y_{22}^{N}-Y_{21}^{N}\right) / Y_{11}^{N}-Y_{12}^{N}$ and only then can the equilibrium solution of equation (6) exist.

Proposition 2. If " $Y_{22}^{N}>Y_{21}^{N}$ and $Y_{11}^{N}<Y_{12}^{N}$, or if $Y_{22}^{N}<Y_{21}^{N}$ and $Y_{11}^{N}>Y_{12}^{N}$, the equilibrium solution does not exist or degenerates.

Proof. According to $E_{K 1}^{N}=E_{K 2}^{N}$, we can deduce $\beta / 1-$ $\beta=Y_{22}^{N}-Y_{21}^{N} / Y_{11}^{N}-Y_{12}^{N}$. As $\beta$ is the probability of "strategy 1 ," there is $0<\beta<1$. Assuming that $Y_{22}^{N}-Y_{21}^{N} / Y_{11}^{N}-Y_{12}^{N}<0$, which conflicts with the condition of $\beta / 1-\beta>0$, the equilibrium solution of equation (6) does not exist or degenerates. 


\section{Case Study}

3.1. Crisis Environment: With the Epidemic as the Background. On January 20, 2020, the National Health Commission of China announced that the 2019-n CoV was classified as Class $\mathrm{B}$ infectious disease and the prevention and control measures of class A were adopted. On January 23, Wuhan city was on lockdown to decrease the risk of infection. Most of the taxi service were suspended, and only a small part of them are used for supporting community emergency and medical staffs' commute. However, the medical pressure in the city is huge, and the commute demand of medical staffs is far from being satisfied. In a state of extreme panic, some ordinary people have a strong desire to leave the city due to various reasons.

Faced with such a situation, a car owner may have two strategies. First, he or she will pick up passengers and send them out of the city through illegal channels for seeking excessive profits, which is a proself decision. Second, be a volunteer and drive medical staffs home free of charge, which is a prosocial decision. After an objective analysis of the pros and cons comprehensively, the matrix of utility under different strategies is shown in Table 1.

The contradiction between the two strategies is how to balance the value conflict between social responsibility and self-interest. Based on their own SVO types, individuals would make subjective interpretation of the objective situation, convert the objective conditions into the subjective utility matrix according to their inner norms of value, give weights to different variables, and adopt corresponding strategies accordingly.

3.2. Distribution of SVO Types. After the crisis environment was described, a questionnaire was prepared using the SVO Slider Measure (Figure 1) mentioned in Section 2.2 in order to grasp the value orientation characteristics of the research objects. After questionnaire recovery, the data were analysed by means of statistical software, and the SVO angle and classification of each person were determined according to mathematical equation (1) and Table 2.

The investigation was focused on college students and 877 students were selected. After eliminating 64 invalid questionnaires with the same answer or incomplete answers, 813 effective questionnaires were taken back. Affected by the epidemic, quantitative data were collected by means of an online survey and students were instructed to complete the questionnaire within the specified time. To verify the retest reliability of the questionnaire, 73 students were randomly selected from the sample to retest at a four-week interval. The results showed that, in the two tests, 56 students were classified into the same SVO type as in the last test, and the measurement consistency was $76.7 \%$.

As a nonparametric estimation method, Kernel Density Estimation can be used to study the data distribution characteristics from the sample itself without any assumptions, so as to compare the differences between groups and achieve good visualization effect. Therefore, based on the KDE method, a program was written in $R$ language to describe the SVO angles distribution of the results, as shown in Figure 5.

According to Figure 5, it can be seen that, in this sample, the distributions of SVO angles are the prosocial orientation type is dominant and the individualistic orientation type is at the second place, followed by the altruistic orientation type and the competitive orientation type. Among the 813 samples, 686 were prosocial orientation $\left(22.45^{\circ} \sim 57.15^{\circ}\right)$, accounting for $84.38 \%$, and distributed in the area near $40^{\circ}$; 75 were individualistic orientation $\left(-12.04^{\circ} \sim 22.45^{\circ}\right)$ accounting for $9.23 \%$; 39 were altruistic orientation $\left(>57.15^{\circ}\right)$, accounting for $4.8 \%$; and 13 were competitive orientation $\left(<-12.04^{\circ}\right)$, accounting for $1.6 \%$.

3.3. Model Construction: A Decision-Making Game Model Based on SVO Difference under the Epidemic Situation. Set the parameters of this game model as follows:

(i) Environment type/En $n_{K}$ : the social environment is regarded as a virtual player 1 and there are 2 strategies ( $K=2$, normal state, epidemic state).

(ii) Social value orientation type/Svo ${ }_{N}$ : it is assumed that player 2 is the owner of the vehicle and the vehicle is in an idle state. In the diagram of SVO angle distribution, the proportion of competitive orientation is very small. If it is included, the reliability and validity of statistical data will be easily affected, so it is omitted. Only three types of altruistic orientation (A), prosocial orientation (B), and individualistic orientation $(\mathrm{C})$ are selected for example analysis. The number of game modules is three.

(iii) Strategies under SVO type $/ S t_{N u}$ : a person with SVO type $N$ exists as player 2 with two strategies $(u=2$, carry passengers illegally or participate in volunteer service).

(iv) $P_{K u}^{N}$ : pyments under strategy $u$ and environment $K$, obtained from the survey data (see Section 3.4).

(v) $G_{K u}^{N}$ : gains under strategy $u$ and environment $K$, obtained from the survey data.

(vi) $a_{K u}^{N} / b_{K u}^{N}$ : to simplify the calculation, given the coefficient $a_{K u}^{N}=b_{K u}^{N}=0.5$.

Based on the above parameters, three game modules are obtained, as shown in Figure 6.

3.4. Equilibrium Analysis: Decision-Making under Different SVO Types. Based on the classification obtained through the SVO Slider Measure, an additional questionnaire was set up to describe the crisis environment (as shown in Section 3.1) and to determine the subjective utility value (including gains and payments) of player 2 when they adopted strategies 1 or 2 under the normal state or epidemic state. The subjective utility value is expressed as any value in the interval $[0,10]$, where the higher the value is, the higher the subjective utility value is when the strategy is selected. The subjective utility values of 813 valid questionnaires were averaged and put 
TABLE 1: Matrix of utility under different strategies.

\begin{tabular}{|c|c|c|}
\hline Strategies & Gains & Payments \\
\hline Proself & Satisfy the needs of some people, extremely high profits & $\begin{array}{l}\text { Endangering public safety and public health, penalty } \\
\text { risk, time, and economic cost }\end{array}$ \\
\hline Prosocial & $\begin{array}{l}\text { Meet the needs of medical staffs, improve medical efficiency, a sense } \\
\text { of accomplishment or satisfaction }\end{array}$ & Risk of infection, time, and economic cost \\
\hline
\end{tabular}

TABLE 2: Common SVO types based on SVO angle.

\begin{tabular}{lcc}
\hline Number & SVO angle & SVO type \\
\hline 1 & $>57.15^{\circ}$ & Altruistic \\
2 & $22.45^{\circ} \sim 57.15^{\circ}$ & Prosocial \\
3 & $-12.04^{\circ} \sim 22.45^{\circ}$ & Individualistic \\
4 & $<-12.04^{\circ}$ & Competitive \\
\hline
\end{tabular}

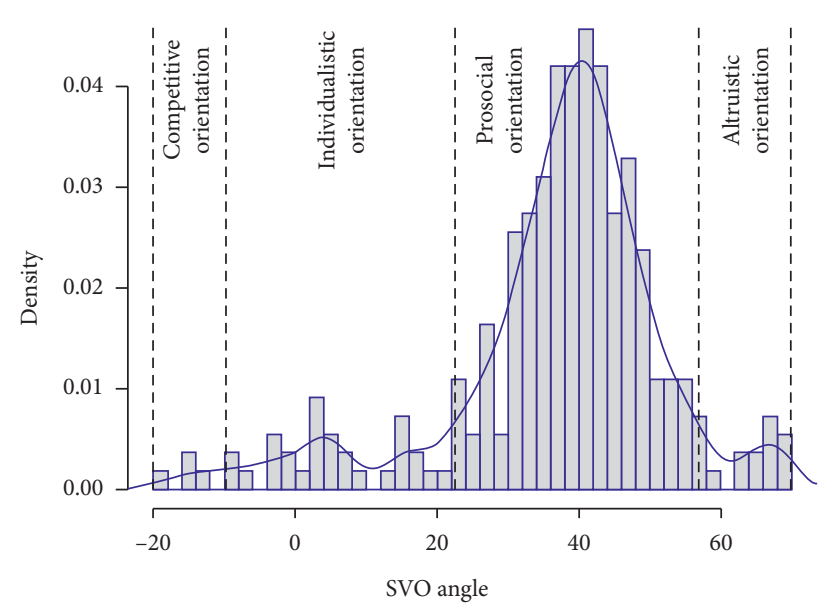

FIGURE 5: Diagram of SVO angle distribution.

\begin{tabular}{|c|c|c|c|c|}
\hline \multirow[b]{2}{*}{ Game module } & \multirow[b]{2}{*}{ SVO type } & Environment & \multicolumn{2}{|c|}{ Social environment } \\
\hline & & Strategy $\quad \begin{array}{c}\text { Subjective } \\
\text { utility function }\end{array}$ & Normal status $(\beta)$ & Epidemic status $(1-\beta)$ \\
\hline \multirow{2}{*}{ SVO.A } & \multirow{2}{*}{$\begin{array}{c}\text { SVO.A } \\
\text { altruistic } \\
\text { orientation }\end{array}$} & $\begin{array}{c}\text { Strategy 1: } \\
\text { carry passengers illegally }\left(\alpha_{A}\right)\end{array}$ & $Y_{11}^{A}=f\left(G_{11}^{A}, P_{11}^{A}\right)$ & $Y_{21}^{A}=f\left(G_{21}^{A}, P_{21}^{A}\right)$ \\
\hline & & $\begin{array}{c}\text { Strategy } 2: \\
\text { participate in volunteer service }\left(1-\alpha_{A}\right)\end{array}$ & $Y_{12}^{A}=f\left(G_{12}^{A}, P_{12}^{A}\right)$ & $Y_{22}^{A}=f\left(G_{22}^{A}, P_{22}^{A}\right)$ \\
\hline \multirow[b]{2}{*}{ SVO.B } & \multirow{2}{*}{$\begin{array}{c}\text { SVO.B } \\
\text { prosocial } \\
\text { orientation }\end{array}$} & $\begin{array}{c}\text { Strategy } 1: \\
\text { carry passengers illegally }\left(\alpha_{B}\right)\end{array}$ & $Y_{11}^{B}=f\left(G_{11}^{B}, P_{11}^{B}\right)$ & $Y_{21}^{B}=f\left(G_{21}^{B}, P_{21}^{B}\right)$ \\
\hline & & $\begin{array}{c}\text { Strategy 2: } \\
\text { participate in volunteer service }\left(1-\alpha_{B}\right)\end{array}$ & $Y_{12}^{B}=f\left(G_{12}^{B}, P_{12}^{B}\right)$ & $Y_{22}^{B}=f\left(G_{22}^{B}, P_{22}^{B}\right)$ \\
\hline \multirow[b]{2}{*}{ SVO.C } & \multirow{2}{*}{$\begin{array}{c}\text { SVO.C } \\
\text { individualistic } \\
\text { orientation }\end{array}$} & $\begin{array}{c}\text { Strategy 1: } \\
\text { carry passengers illegally }\left(\alpha_{C}\right)\end{array}$ & $Y_{11}^{C}=f\left(G_{11}^{C}, P_{11}^{C}\right)$ & $Y_{21}^{C}=f\left(G_{21}^{C}, P_{21}^{C}\right)$ \\
\hline & & $\begin{array}{c}\text { Strategy } 2: \\
\text { participate in volunteer service }\left(1-\alpha_{C}\right)\end{array}$ & $Y_{12}^{C}=f\left(G_{12}^{C}, P_{12}^{C}\right)$ & $Y_{22}^{C}=f\left(G_{22}^{C}, P_{22}^{C}\right)$ \\
\hline
\end{tabular}

Figure 6: Game modules when SVO type is A, B, and C. 


\begin{tabular}{|c|c|c|c|c|c|c|c|c|}
\hline \multirow{3}{*}{$\begin{array}{l}\text { Game } \\
\text { module }\end{array}$} & \multirow{3}{*}{ SVO type } & \multirow[b]{3}{*}{ Strategy } & \multicolumn{6}{|c|}{ Social environment } \\
\hline & & & \multicolumn{3}{|c|}{ Normal status $(\beta)$} & \multicolumn{3}{|c|}{ Epidemic status $(1-\beta)$} \\
\hline & & & $G_{1 u}^{N}$ & $P_{1 u}^{N}$ & $Y_{1 u}^{N}$ & $G_{2 u}^{N}$ & $P_{2 u}^{N}$ & $Y_{2 u}^{N}$ \\
\hline \multirow[b]{2}{*}{ SVO.A } & \multirow{2}{*}{$\begin{array}{c}\text { SVO.A } \\
\text { altruistic } \\
\text { orientation }\end{array}$} & $\begin{array}{l}\text { Strategy 1: } \\
\text { carry passengers illegally }\left(\alpha_{A}\right)\end{array}$ & 5.65 & 1.14 & 2.26 & 0.00 & 9.45 & -4.73 \\
\hline & & $\begin{array}{l}\text { Strategy 2: } \\
\text { participate in volunteer service }\left(1-\alpha_{A}\right)\end{array}$ & 5.79 & 1.05 & 2.37 & 9.24 & 6.18 & 1.53 \\
\hline \multirow{2}{*}{ SVO.B } & \multirow{2}{*}{$\begin{array}{c}\text { SVO.B } \\
\text { prosocial } \\
\text { orientation }\end{array}$} & $\begin{array}{c}\text { Strategy 1: } \\
\text { carry passengers illegally }\left(\alpha_{B}\right)\end{array}$ & 6.28 & 1.35 & 2.47 & 0.54 & 8.35 & -3.91 \\
\hline & & $\begin{array}{c}\text { Strategy 2: } \\
\text { participate in volunteer service }\left(1-\alpha_{B}\right)\end{array}$ & 4.86 & 2.43 & 1.22 & 3.12 & 7.21 & -2.06 \\
\hline \multirow{2}{*}{ SVO.C } & \multirow{2}{*}{$\begin{array}{c}\text { SVO.C } \\
\text { individualistic } \\
\text { orientation }\end{array}$} & $\begin{array}{c}\text { Strategy 1: } \\
\text { carry passengers illegally }\left(\alpha_{C}\right)\end{array}$ & 6.58 & 1.41 & 2.59 & 3.52 & 7.52 & -2.00 \\
\hline & & $\begin{array}{c}\text { Strategy } 2: \\
\text { participate in volunteer service }\left(1-\alpha_{C}\right)\end{array}$ & 2.75 & 2.85 & -0.05 & 0.36 & 8.55 & -4.10 \\
\hline
\end{tabular}

Figure 7: Subjective utility matrix when SVO type is A, B, and C.

into equation (2) to obtain the value $Y_{K u}^{N}$, as shown in Figure 7.

According to $t$ Figure 7 and steps of equilibrium analysis in Section 2.4, the case analysis is as follows.

(1) Game module of SVO.A:

From the subjective utility matrix, solving $E_{K 1}^{A}=E_{K 2}^{A}$, then $\beta=1.0347$, which conflicts with the condition $0<\beta<1$ and verifies the correctness of Proposition 2. According to the four subjective utility values, $2.37>2.26>1.53>-4.73$, which means that the analysis of equilibrium degenerates into a general optimization problem, and the dominant strategy is "under normal conditions, a person who is classified into altruistic orientation type (SVO.A) would participate in volunteer service."

Draw the function graphs of $E_{K 1}^{A}$ and $E_{K 2}^{A}$ (see Figure 8). In Figure 8, the blue line represents the utility for strategy 1 (proself), and the red line represents the utility for strategy 2 (prosocial). It can be seen that whenever people of SVO. A type would choose "prosocial" strategy, the subjective utility value would be greater than that of "proself" strategy. Such decision-making is relatively stable and conform to the realistic characteristics of the type.

(2) Game module of SVO.B:

From the subjective utility matrix, solving $E_{K 1}^{B}=E_{K 2}^{B}$, then $\beta=0.5978$, which satisfies the condition of $0<\beta<1$, and the equilibrium state is as following. If the probability of the social environment (player 1) choosing strategy 1 (normal operation) is $59.78 \%$, the game reaches the equilibrium. The utility value is the same whether the person of type B (prosocial orientation) chooses strategy 1 or strategy 2 , which is -0.1026 . The correctness of Proposition 1 is verified.

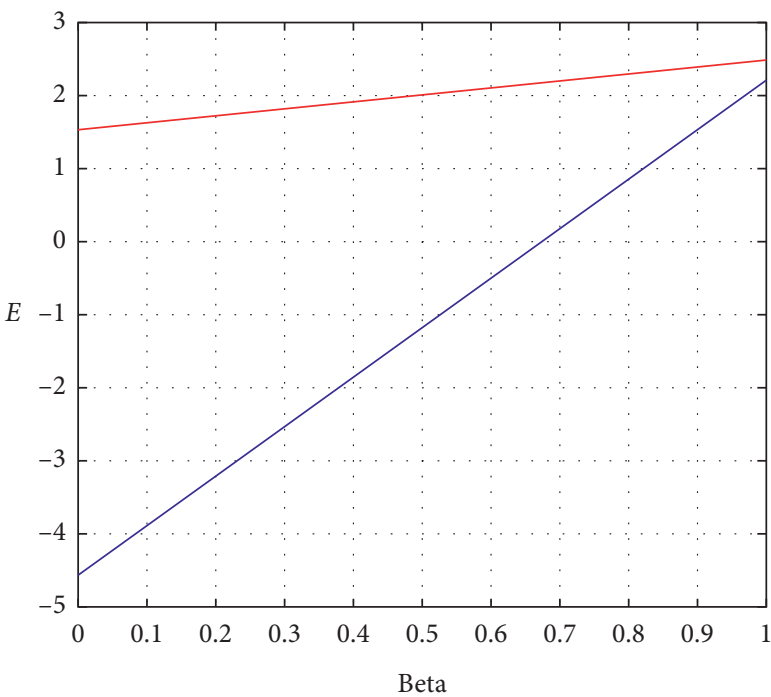

- $E 1=6.89^{*}$ beta -4.73

- E2 $=0.84^{*}$ beta +1.53

Figure 8: Function graphs of $E_{K 1}^{A}$ and $E_{K 2}^{A}$.

(ii) Draw the function graphs of $E_{K 1}^{B}$ and $E_{K 2}^{B}$ (see Figure 9). In the figure, the blue line represents the utility for strategy 1 (proself) and the red line represents the utility for strategy 2 (prosocial). It can be seen that when the probability of the social environment (player 1) choosing strategy 1(normal operation) is within the range of $[0,0.5978]$, the utility value of the prosocial strategy is greater than that of the other strategy; when the probability is in the range of $[0.5978,1]$, the opposite is true. This means that the decision-making of such SVO type is greatly influenced by the crisis environment, and the impact factors and results are relatively complex. 


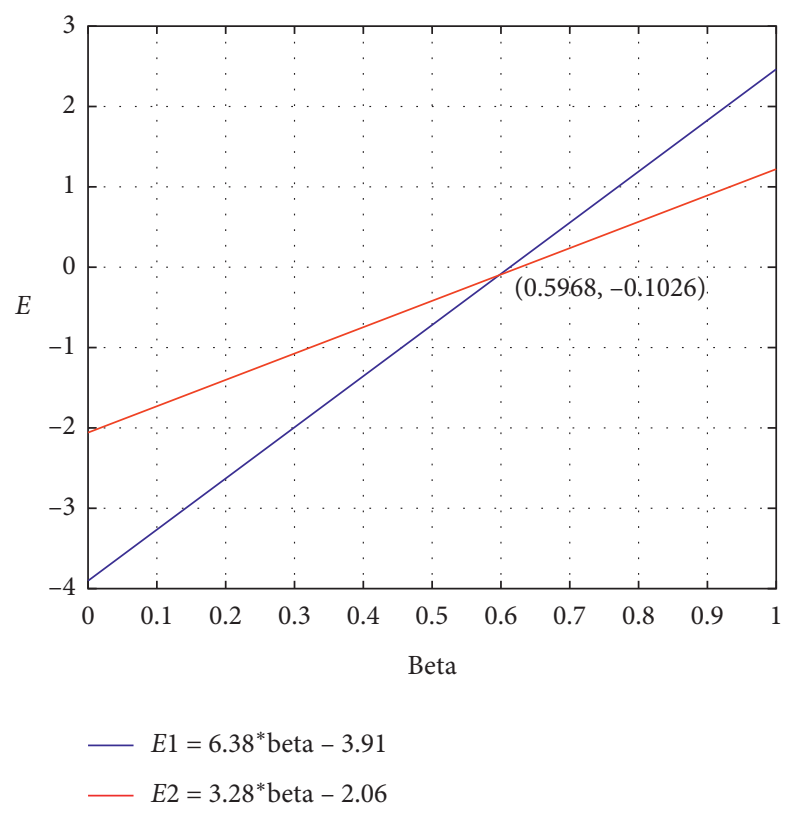

FIgURE 9: Function graphs of $E_{K 1}^{B}$ and $E_{K 2}^{B}$.

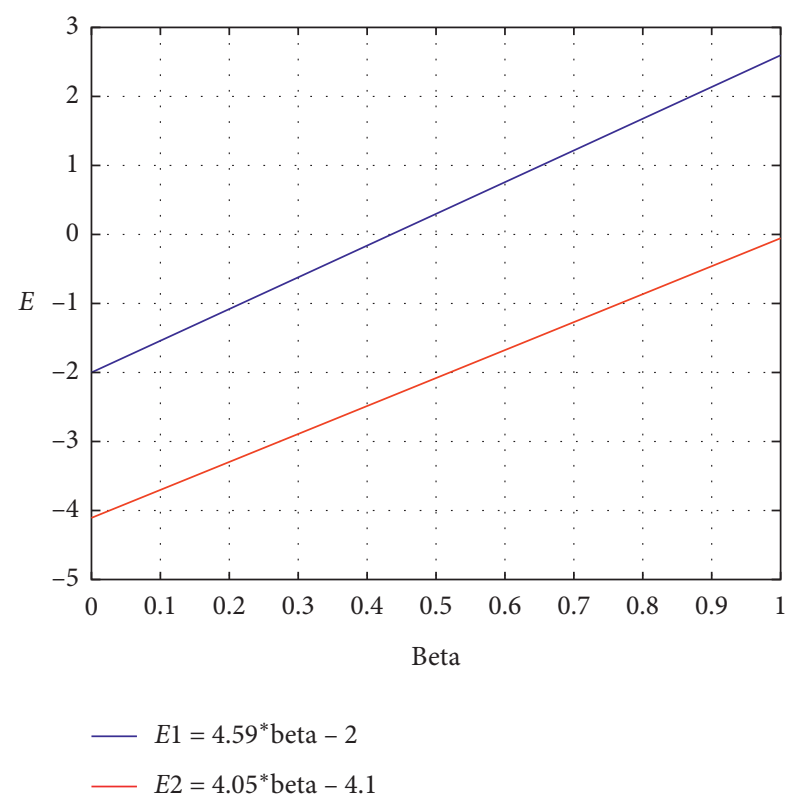

Figure 10: Function graphs of $E_{K 1}^{C}$ and $E_{K 2}^{C}$.

(3) Game module of SVO.C:

From the subjective utility matrix, solving $E_{K 1}^{C}=E_{K 2}^{C}$ yields $\beta=-3.889$, which conflicts with the condition $0<\beta<1$, and verifies the correctness of Proposition 2. According to the four subjective utility values, $2.59>-0.05>-2.00>-4.10$, which means that the analysis of equilibrium degenerates into a general optimization problem, and the dominant strategy is "under normal conditions, a person who is classified into individualistic orientation type (SVO.C) would carry passengers illegally". (ii) Draw the function graphs of $E_{K 1}^{C}$ and $E_{K 2}^{C}$ (see Figure 10). In the figure, the blue line represents the utility for strategy 1 (proself), and the red line represents the utility for strategy 2 (prosocial). It can be seen that, at any time, the subjective utility value function of a person of SVO.C type choosing the "proself" strategy will be greater than that of the "prosocial" strategy. Such decision-making is relatively stable and conform to the realistic characteristics of the type.

Through the analysis of the above three game modules, it can be found that, in the same social environment, people of different SVO types will form different subjective utility matrix based on their inner value norms, preferences, and orientations. The results of equilibrium analysis show that, in the crisis environment, both types SOV.A and SOV.C have a dominant strategy, and type SVO.B has a Nash equilibrium, which are consistent with their actual characteristics. It does not mean that types SOV.A and SOV.C are not affected by the environment, and it shows that there is a certain mapping relationship between people's SVO types and decisionmaking. Such a relationship could be more obvious in the crisis environment. Human is the sum of social relations, and the social value orientation of human is dynamic rather than static, but once a certain type is formed, it has relative stability and persistence, and the decisions he or she makes will be based on the characteristics of their type belongings.

\section{Conclusion}

Through four steps of "describing environment, determining SVO type, and constructing game model and equilibrium analysis," the mapping relationship and game mechanism of SVO types and decision-making are analysed in crisis environment. Case analysis confirmed the effectiveness of the SVO Slider Measure in determining people's SVO types. With the "subjective utility value" as the intermediary, the proself and prosocial strategy adaptation mechanism for the individuals with altruistic, prosocial, and individual-orientation in crisis environment is further analysed. It is shown that individuals' decision-making will be affected by the social environment, but what this paper points out is that, in a specific environment, especially in a crisis environment, individuals with different social value orientations will adopt strategies with certain regularity. According to the equilibrium analysis, the decision of individuals of type SVO.A and type SVO.B tend to be more stable than that of type SVO.C. This study provides a visible equilibrium analysis chart of the game model to describe the invisible value orientation, decision-making, and the mapping relationship by means of quantitative and modelling methods, which provides a research perspective for the study of decisionmaking mechanism of individuals with different SVO types and complements qualitative analysis of other studies as well.

\section{Data Availability}

The data used to support the findings of this study are included within the article. For more details, the data are available from the corresponding author upon request. 


\section{Conflicts of Interest}

The authors declare that they have no conflicts of interest.

\section{Acknowledgments}

This work was supported by the Key Project of Philosophy and Social Science Research in Colleges and Universities of Jiangsu Province (2018SJZDI180).

\section{References}

[1] E. Marx, Anthology of Marx and Engels, Vol. 1, People's Publishing House, Beijing, China, 2012.

[2] H. Liu and Y. Liu, "The modern value dilemma of mainstream value identification," Journal of Jishou University, vol. 33, no. 1, pp. 61-64, 2012.

[3] S. Wang and L. Chang, "Reflection and transcendence of the cultivation of my country 's core values," Marxism Research, no. 2, pp. 143-150, 2017.

[4] Y. Zhang, "Core value order and socialist core values," Teaching and Research, vol. 47, no. 6, pp. 47-53, 2013.

[5] B. Liao, Z. Yu, and V. Ryan, "Practical reasoning about norms, values and preferences," Journal of Tsinghua University, vol. 34, no. 2, pp. 140-149, 2019.

[6] Z. Li and L. Yang, "The current situation and characteristics of the development of college students "values in the new era," School Party Building and Ideological Education, vol. 24, no. 24, pp. 18-20, 2019.

[7] B. Xing, Z. Wu, H. Liu, and C. Xiong, "Analysis of the values of college students in the perspective of contemporary social changes," Journal of Jishou University, vol. 40, no. S1, pp. 24-27, 2019.

[8] E. Heim, S. Scholten, A. Maercker et al., 'Students' value orientations in contemporary China: analysis of measurement invariance and latent mean differences in comparison with students from Germany and Russia," Journal of Cross-Cultural Psychology, vol. 48, no. 4, 2017.

[9] J. Ji, "The value orientation of truth, goodness and beauty of youth 's ideal personality in the new era," Ideological and Educational Guide, no. 2, pp. 65-68, 2020.

[10] Y. Fan and C. Xu, "The content category and value orientation of Xi Jinping 's youth ideology in the new era," Reference for Political Teaching in Middle Schools, no. 6, pp. 63-64, 2019.

[11] X. Chen, "The totality of human development value orientation," Journal of Peking University, vol. 54, no. 1, pp. 17-24, 2017.

[12] G. M. Hodgson, "“On the limits of rational choice theory," economic thought," World Economics Association, vol. 1, no. 1, pp. 1-5, 2012.

[13] V. Lange and A. M. Paul, "Beyond self-interest: a set of propositions relevant to interpersonal orientations," European Review of Social Psychology, vol. 11, no. 1, pp. 297-331, 2000.

[14] P. A. Van Lange, E. M. De Bruin, W. Otten, and J. A. Joireman, "Development of prosocial, individualistic, and competitive orientations: theory and preliminary evidence," Journal of Personality and Social Psychology, vol. 73, no. 4, pp. 733-746, 1997.

[15] C. Liu and H. Fang, "The influence of social value orientation on cooperation in asymmetric social dilemma," Psychology, no. 4, pp. 90-99, 2011.

[16] B. Yang and S. Tian, "“Snowstorm": extreme humanity in extreme environment," Contemporary Film, no. 6, pp. 27-29, 2019, http://www.cnki.com.cn/Article/CJFDTotal-DDDY201906006. htm.
[17] Z. Wang, "Reflections on humanity in extreme situations--on wang zengqi's "political subject" novels," Contemporary Writers' Review, no. 2, pp. 102-108, 2020.

[18] P. Kollock, "Social dilemmas: the anatomy of cooperation," Annual Review of Sociology, vol. 24, no. 1, pp. 183-214, 1998.

[19] T. Xu, Y. Liu, P. Hu, and S. Peng, "Use of moral dilemma paradigm in psychological research: retrospect and prospect," Chinese Journal of Clinical Psychology, vol. 26, no. 3, pp. 458-461, 2018.

[20] Yi Ding, T. Ji, and C. Xu, "Cooperative choice in a social dilemma: the trade-off between self-interest and collective interest," Psychological Exploration, vol. 35, no. 2, pp. 159-164, 2015.

[21] J. D. Greene, "An fMRI investigation of emotional engagement in moral judgment," Science, vol. 293, no. 5537, pp. 2105-2108, 2001.

[22] M. Carmona-Perera, A. Caracuel, M. Pérez-García et al., "Brief moral decision-making questionnaire: a rasch-derived short form of the greene dilemmas," Psychological Assessment, vol. 27, no. 2, pp. 424-432, 2015.

[23] J. Zhang, "The application of the "dilemma discussion" model of moral education in the teaching of "ideological moral cultivation and legal foundation," Ideological Education Research, no. 1, pp. 88-92, 2018.

[24] Y. Sun, "Demonstration of "other" in moral dilemma education," Chinese Journal of Education, no. 4, pp. 86-92, 2018.

[25] A. Liu, "Thoughts on moral education triggered by "moral dilemma education model," Chinese Journal of Education, no. 5, pp. 58-61, 2015, http://www.cnki.com.cn/Article/ CJFDTotal-ZJYX201804020.htm.

[26] G. Zheng, "Practical inspiration and reflection of the Porter model- - theoretical and practical analysis of moral reasoning in the ethical decision model of behavior," Ethics Research, no. 3, pp. 73-77, 2012.

[27] J. Tang and Z. He, "Discussion on Kidd 's ethical choice model and its integration into Chinese values - an alternative to the Porter model," Journal of Social Science of Hunan Normal University, vol. 49, no. 1, pp. 109-119, 2020.

[28] C. G. McClintock and W. B. Liebrand, "Role of interdependence structure, individual value orientation, and another's strategy in social decision making: a transformational analysis," Journal of Personality and Social Psychology, vol. 55, no. 3, pp. 396-409, 1988.

[29] M. Bieleke, D. Dohmen, M. Peter, and Gollwitzer, "Effects of social value orientation (SVO) and decision mode on controlled information acquisition-a Mouselab perspective," Journal of Experimental Social Psychology, vol. 86, 2020.

[30] Y. Jin and C. Wang, "Utilization feature conversion of task structure and value orientation under dilemma," Psychology, no. 5, pp. 529-533, 2002.

[31] M. Wu, "Research on moral decision-making under different social value orientations," Decision and Information, no. 4, pp. 62-65, 2017.

[32] J. Zhang, "The characteristics and education countermeasures of undergraduates receiving ideological and political education under the new media environment," Heilongjiang Higher Education Research, vol. 37, no. 7, pp. 145-148, 2019.

[33] Z. Tan and J. Fang, "On the internal logic of the ecological value of environmental education and ideological and political education-_also on the Marxist view of ecological environment," School Party Construction and Ideological Education, no. 21, pp. 33-35, 2016.

[34] P. A. M. Van Lange, "The pursuit of joint outcomes and equality in outcomes: an integrative model of social value 
orientation," Journal of Personality and Social Psychology, vol. 77, no. 2, pp. 337-349, 1999.

[35] Z. Zhang, F. Zhang, L. Huang, B. Yuan, and Y. Wang, "Theories and measurement methods of social value orientation related to decision making," Advances in Psychological Science, vol. 22, no. 1, pp. 48-56, 2014.

[36] P. Wang and L. Chen, "The effect of punishment and social value orientation on interpersonal trust and cooperative behavior in the public goods dilemma," Psychology, vol. 43, no. 1, pp. 52-64, 2011.

[37] B. Sandy, B Christophe, and C. Declerck, "Social value orientation and cooperation in social dilemmas: a review and conceptual model," British Journal of Social Psychology, vol. 47, no. 3, 2008.

[38] K. Kanagaretnam, S. Mestelman, K. Nainar, and M. Shehata, "The impact of social value orientation and risk attitudes on trust and reciprocity," Journal of Economic Psychology, vol. 30, no. 3, pp. 368-380, 2009.

[39] J. L. Pletzer, D. Balliet, J. Joireman, D. M. Kuhlman, S. C. Voelpel, and P. A. M. Van Lange, "Social value orientation, expectations, and cooperation in social dilemmas: a meta-analysis," European Journal of Personality, vol. 32, no. 1, pp. 62-83, 2018.

[40] Y. Qi, H. Wu, and X. Liu, "The influences of social value orientation on prosocial behaviors: the evidences from behavioral and neuroimaging studies," Chinese Science Bulletin, vol. 62, no. 11, pp. 1136-1144, 2017.

[41] R. O. Murphy and K. A. Ackermann, "Social value orientation: theoretical and measurement issues in the study of social preferences," Personality \& Social Psychology Review, vol. 18, no. 1, 2014. 